\title{
Erratum to: Interactive Effects of Prenatal Antidepressant Exposure and Likely Gene Disrupting Mutations on the Severity of Autism Spectrum Disorder
}

\author{
Sean Ackerman ${ }^{1} \cdot$ Sarah Schoenbrun $^{2} \cdot$ Caitlin Hudac $^{3} \cdot$ Raphael Bernier $^{4}$
}

Published online: 8 September 2017

(c) Springer Science+Business Media, LLC 2017

\section{Erratum to: J Autism Dev Disord}

DOI 10.1007/s10803-017-3246-6

The original version of this article unfortunately contained a mistake. The spelling of the co-author's name was incorrect. The correct name is Sarah Schoenbrun

The original article has been corrected.

The online version of the original article can be found under doi:10.1007/s10803-017-3246-6.

Sean Ackerman

sean.ackerman@ssmhealth.org

Sarah Schoenbrun

sschoenb@uw.edu

Caitlin Hudac

chudac@uw.edu

Raphael Bernier

rab2@uw.edu

1 Department of Psychiatry, Child \& Adolescent Psychiatry,

SSM Dean Medical Group, 1313 Fish Hatchery Rd,

Madison, WI 53715, USA

2 School of Medicine, University of Washington, Seattle, WA, USA

3 Department of Psychiatry, University of Washington, Seattle, WA, USA

4 Department of Psychiatry and Center on Human Development and Disability, University of Washington, Seattle, WA, USA 